\title{
Familial Adenomatous Polyposis and Benign Intracranial Tumors: A New Variant of Gardner's Syndrome
}

\author{
Richard Leblanc
}

\begin{abstract}
Introduction: Familial adenomatous polyposis (FAP) is associated with malignant tumors of the central nervous system, predominantly medulloblastomas and glioblastoma multiforme (Turcot's syndrome) and with craniofacial osteomas (Gardner's syndrome). This report details the occurrence of benign, intracranial tumors in two related individuals with Gardner's syndrome, an association not previously described. Patients and methods: A 57-year-old woman (the propositus), her sister, two of her nieces and one of her grandnephews were previously diagnosed with Gardner's syndrome. The propositus came to neurosurgical attention because of vertigo associated with what proved to be an epidermoid cyst of the cerebellopontine angle. Her unaffected children and her relatives with Gardner's syndrome were examined and underwent computed tomography or magnetic resonance imaging. Results: A 39-year-old woman with Gardner's syndrome, the niece of the propositus, was found to harbor an asymptomatic left frontal meningioma. Discussion: Familial adenomatous polyposis, Gardner's syndrome, and that variant of Turcot's syndrome in which medulloblastoma predominate, are associated with a mutation of the adenomatous polyposis coli gene. The demonstration that patients with Gardner's syndrome can also have benign, nonneuroglial, intracranial tumors adds to the previously known extracolonic lesions associated with FAP. The molecular characterization of our patients should reveal if benign intracranial tumors represent a pleiotropic manifestation of the adenomatous polyposis coli gene mutation or if other genes are implicated.
\end{abstract}

RÉSUMÉ: Polypose adénomateuse familiale et tumeurs intracrâniennes bénignes: une nouvelle variante du syndrome de Gardner. Introduction: La polypose adénomateuse familiale est associée à des tumeurs malignes du système nerveux central, surtout des médulloblastomes et des glioblastomes multiformes (syndrome de Turcot), et à des ostéomes crâniofaciaux (syndrome de Gardner). Cet article rapporte une association qui n'a pas été décrite antérieurement: la présence de tumeurs intracrâniennes bénignes chez deux individus apparentés présentant un syndrome de Gardner. Patients et méthodes: Un diagnostic de syndrome de Gardner avait été posé antérieurement chez une femme âgée de 57 ans (le cas index), sa sœur, deux de ses nièces et un de ses petits-neveux. Le cas index a été référé en neurochirurgie à cause de vertiges associés à ce qui s'est avéré être un kyste épidermoïde de l'angle ponto-cérébelleux. Ses enfants non atteints et les membres de sa parenté atteints du syndrome de Gardner ont été examinés et ont subi une tomodensitométrie ou une résonance magnétique. Résultats: On a découvert un méningiome frontal gauche asymptomatique chez une nièce du cas index, une femme âgée de 39 ans atteinte du syndrome de Gardner. Discussion: La polypose adénomateuse familiale, le syndrome de Gardner et la variante du syndrome de Turcot où le médulloblastome prédomine sont associés à une mutation du gène de la polypose adénomateuse colique. La démonstration que les patients porteurs du syndrome de Gardner peuvent également avoir des tumeurs bénignes intracrâniennes non neurogliales s'ajoute à ce qui est déjà connu sur les lésions extracoliques associées à la polypose adénomateuse familiale. La caractérisation moléculaire de nos patients devrait nous indiquer si les tumeurs intracrâniennes bénignes représentent une manifestation pleiotrope de la mutation du gène de l'APC ou si d'autres gènes sont en cause.

Can. J. Neurol. Sci. 2000; 27: 341-346

Familial adenomatous polyposis (FAP) is an autosomal dominant disorder arising from a germ-line mutation of the adenomatous polyposis coli (APC) gene located on chromozome 5. ${ }^{1}$ Familial adenomatous polyposis is characterized by the presence of a multitude of adenomatous polyps in the large intestine that inexorably evolve into colonic cancers unless the colon is resected. The association of FAP and malignant cerebral tumors is referred to as Turcot's syndrome. The association of FAP with osteomas of the skull and facial bones and with soft tissue tumors constitutes Gardner's syndrome. ${ }^{2}$ The author reports the occurrence of benign intracranial tumors (an epidermoid cyst and a meningioma) in an aunt and niece with Gardner's syndrome, a previously unrecognized extra-colonic manifestation of FAP.

From the Department of Neurology and Neurosurgery, Montreal Neurological Institute, McGill University, Montreal, Quebec, Canada.

Received March 8, 2000. AcCePted infinalform August 1, 2000. Reprint requests to: R. Leblanc, 3801 University Street, Montreal, QC H3A2B4, Canada. 


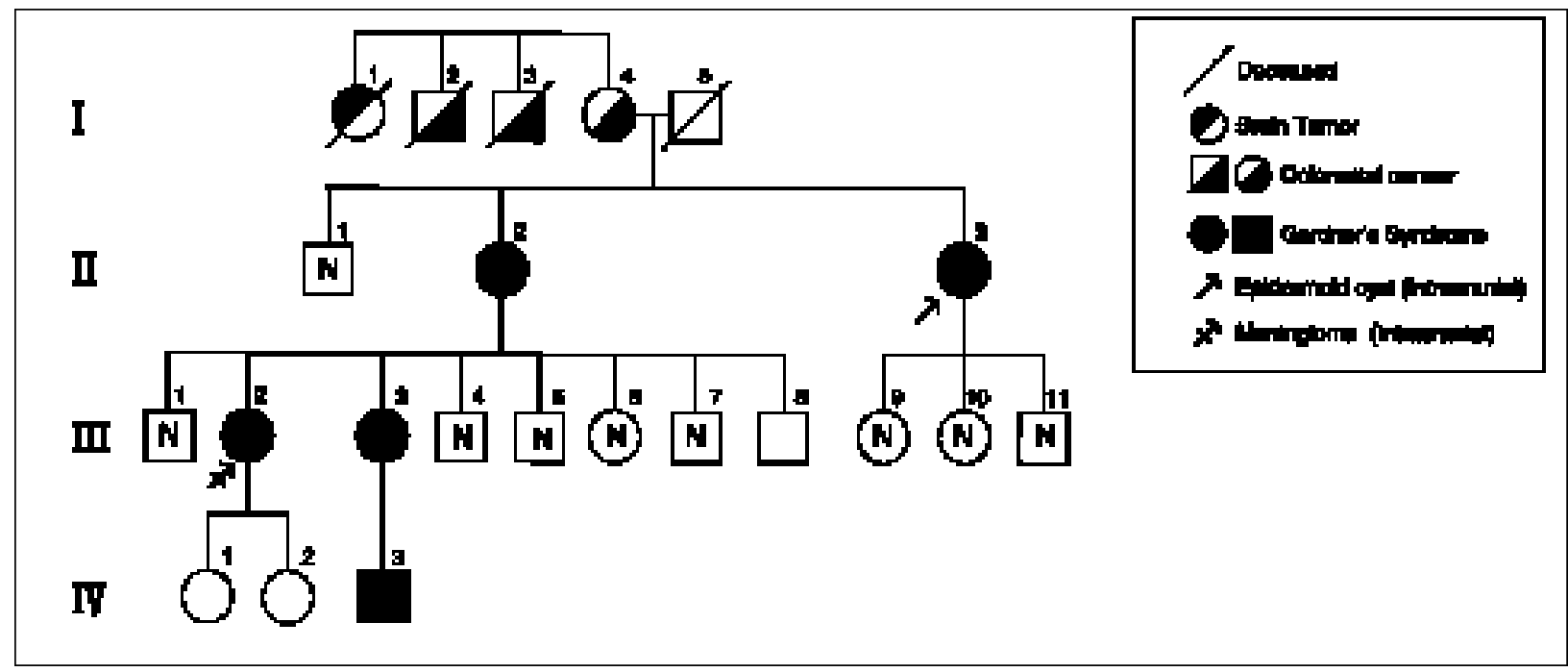

Figure 1: Pedigree: Individual I-1 is reported to have died of a cerebral tumour. Individuals I-2 \& 3 are reported to have died of colonic cancer. Individual I-4 has a documented colonic adenocarcinoma. Individuals II-2, 3, III-2,3, and IV-3 have documented Gardner's syndrome. Individuals II-3 and III-2 have Gardner's syndrome and, respectively, an intracranial epidermoid cyst and a meningioma.

\section{Patients ANd Methods}

The family is of French-Canadian origin. A patient, the propositus, previously diagnosed with Gardner's syndrome, came to neurosurgical attention because of an intracranial spaceoccupying lesion. The members of her family were offered consultation and elective computed tomographic (CT) or magnetic resonance imaging (MRI) screening for the presence of intracranial lesions. Thus, the propositus'children, her sister and one of her nieces were interviewed, examined and underwent radiological investigation. Another niece and her son were interviewed by telephone but refused examination. Additional details concerning the family were obtained from the propositus and her sister, from medical records and from physicians who had attended various members of the family. The detailed pedigree is presented in Figure 1.

Individual I-1 is reported to have died from a cerebral tumor and individuals I-2 and 3 are reported to have died from intestinal cancer. No further details are available.

Individual I-4, aged 88 years, underwent resection of a colonic adenocarcinoma. She is free of visible facial osteomas.

Individual I-5 died at age 45 of myocardial infarction.

Individual II-1, aged 55 years, has undergone sigmoidoscopies for FAP that have been negative to date.

Individual II-2, aged 59 years, the sister of the propositus, was diagnosed with Gardner's syndrome at age 18 and underwent an elective hemicolectomy at the time. She has also undergone salpingo-oophorectomy for a benign cyst of the adnexa. She had no neurological complaints and her neurological examination was normal. She had visible and palpable, hard and immobile bony excrescences of the mandible measuring approximately $1-2 \mathrm{~cm}$ in diameter and diagnosed clinically as osteomas. A high-resolution, 3-dimensional, helical CT scan of the brain performed after the intravenous infusion of contrast material identified osteomas of the right and left ethmoid bones but no intracranial pathology.
Individual II-3, the propositus, was in apparent good health until, as a young adult, she presented to hospital after a fall. Characteristic facial osteomas were observed (Figure 2). Subsequent radiological investigation and ultimately histological examination of the electively resected colon, which contained innumerable adenomatous polyps, established the diagnosis of FAP and Gardner's syndrome. She came to neurosurgical attention at the age of 57 years after a MRI scan performed for the investigation of vertigo had demonstrated an intracranial lesion. She gave a history of her previous abdominal surgery and of resection of a lipoma of the scalp. Her general physical examination was unremarkable except for the presence of scars on the abdomen and scalp and of subcutaneous, nontender, bony

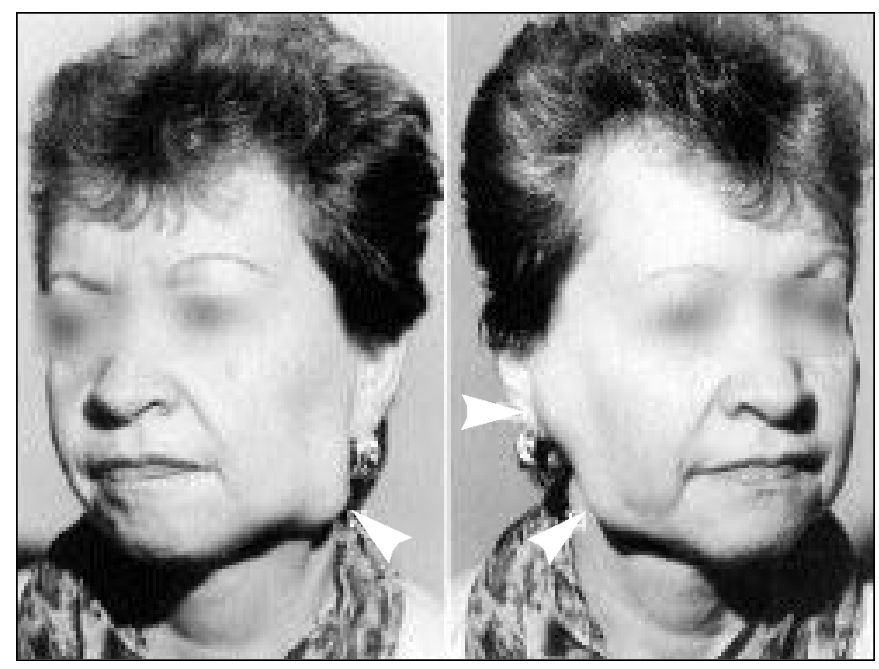

Figure 2: Photographs of Individual II-3, with Gardner's syndrome and an intracranial epidermoid cyst demonstrating facial osteomas (arrows). 

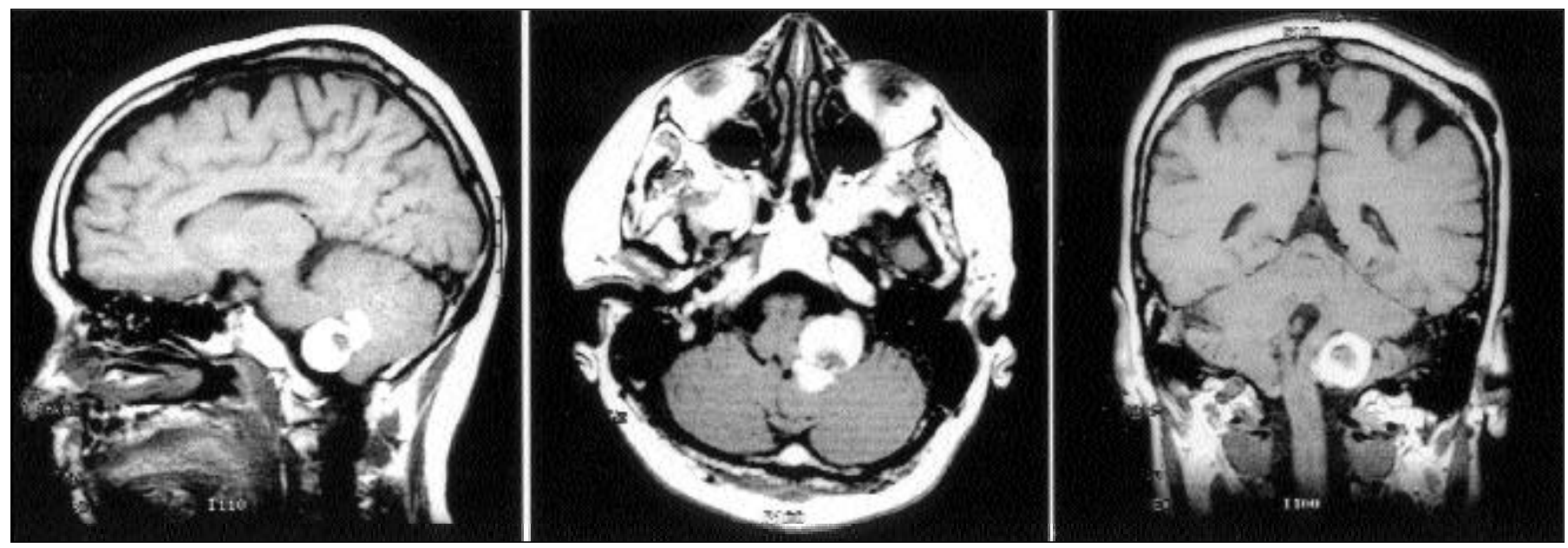

Figure 3: Noninfused T1-weighted MRI scan of Individual II-3 demonstrating a hyperintense extra-axial lesion within the cerebello-pontine angle distorting the brain stem and cerebellum and documented histologically to be an epidermoid cyst with areas of hemorrhage.

lesions of the angles and ascending rami of the mandible. Chest $\mathrm{x}$-rays and electrocardiogram were normal, as were urinalysis, complete blood count, serum electrolytes, and liver and renal function tests. Computed tomography scanning and MRI confirmed the nature of the mandibular lesions as osteomas, and identified the intracranial lesion. This appeared as a nonenhancing, hyperdense lesion of the cerebellopontine (CP) angle on CT scanning. Magnetic resonance imaging revealed a hyperdense, intradural, extraparenchymal lesion of the left $\mathrm{CP}$ angle compressing the cerebellar hemisphere and fourth ventricle (Figure 3). It only faintly and partially enhanced with the intravenous infusion of gadolinium but the hyperintensity of the pre-infusion signal made the infused study difficult to interpret. At surgery, the cyst was noted to occupy the subarachnoid space of the $\mathrm{CP}$ angle, insinuating itself between the vertebral artery and lower cranial nerves to which it was adherent, and displacing the pons and cerebellum where its capsule was adherent to the pia-arachnoid. The cyst capsule was thin and glistening and contained semigelatinous, xanthochromic fluid. The cyst contents were completely evacuated and its capsule excised where this did not compromise the vasculature or the integrity of neural tissue. Histological examination of the surgically resected specimen revealed a cyst wall lined by squamous epithelium. There was abundant acellular laminated material consistent with compressed keratin, and one section showed an area of old hemorrhage. It was classified histologically as an epidermoid cyst (Figure 4). The patient's postoperative course was unremarkable and satisfactory except for mild, transient vocal cord dysfunction.

Individuals III-1, 4, 5, 6, 7, and 8 refused consultation and examination. Individuals III 1, and 4-7 have undergone sigmoidoscopies for FAP which have been negative. Individual III-8 has refused sigmoidoscopy.

Individual III-2, aged 39 years, was diagnosed with Gardner's syndrome at the age of 20 because of the presence of facial osteomas and after investigation for hematochelia had demonstrated the presence of FAP. She underwent a hemicolectomy which confirmed the diagnosis. She had previously sought neurological consultation for poorly characterized and nonobjectified hemisensory complaints, headaches and dizziness. A noninfused MRI scan had been obtained to rule out multiple sclerosis (MS). Although showing no evidence of MS, it did uncover a left frontal space-occupying lesion. Her general examination revealed the presence of osteomas involving the maxilla. Her neurological examination was unremarkable. An MRI performed after the intravenous infusion of gadolinium was reviewed with her previous noninfused MRI (Figure 5). These revealed the presence of an

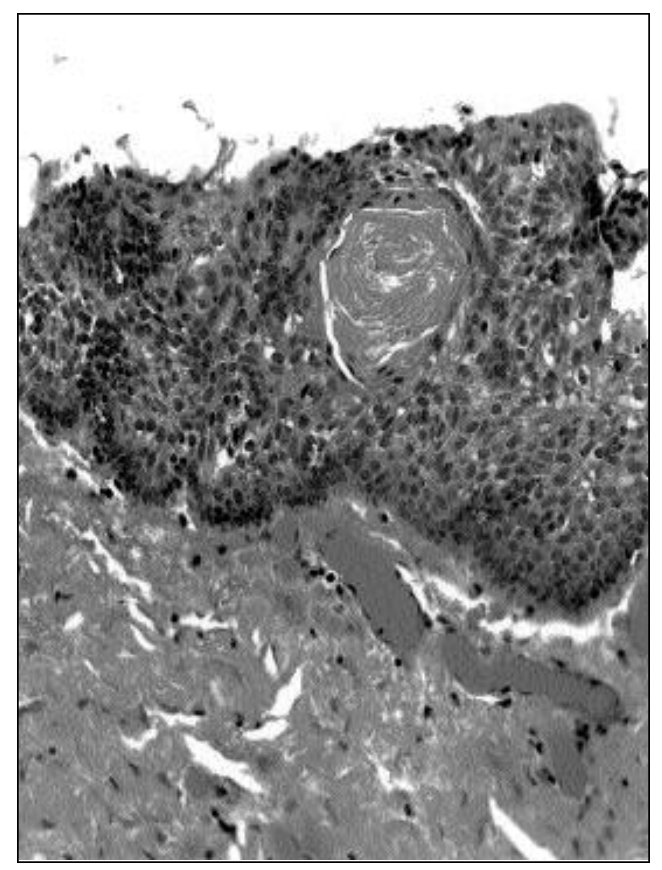

Figure 4: Histological section of the intracranial lesion removed from individual II-3 demonstrating the presence of squamous epithelium and keratin inclusions. An area of hemorrhage with associated hemosiderin laden macrophages was seen in other sections. Hematoxilin and eosin, 150X. 

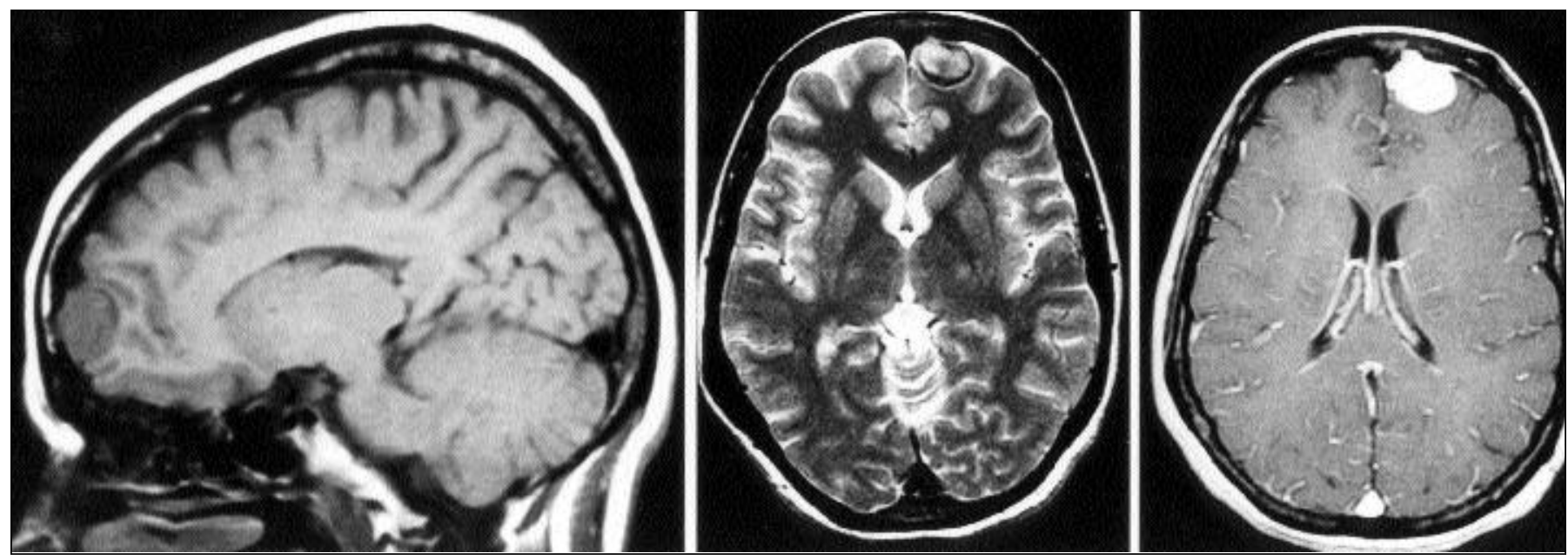

Figure 5: MRI scan of Individual III-2 demonstrating a left extra-axial frontal lesion isodense in T1 and T2 that enhances with the infusion of gadolinium. A confident diagnosis of meningioma was made.

intradural, extraparenchymal, gadolinium-enhancing, $1 X 1.6 \mathrm{~cm}$ space-occupying lesion associated with an enlarged pacchionian granulation, nesting on the surface of the left frontal lobe. There was no associated edema or shift of the cerebral hemisphere. Three experienced neuroradiologists made a confident diagnosis of meningioma. An osteoma of the left frontal air sinus was also present. The patient refused neurosurgical follow-up but voiced no complaints when contacted by telephone two and a half years later.

Individual III-3, aged 41 years, underwent elective hemicolectomy at age 26 years for histologically-confirmed FAP. She has also undergone resections of a recurrent desmoid tumor of the abdominal wall and of a benign adenoma of the right adrenal gland. She has no visible facial osteomas. A CT scan of the head performed after the intravenous infusion of contrast material was reported normal.

Individuals III-9, 10, and 11, aged 30-36 years, have been followed regularly with elective sigmoidoscopies which have been normal to date. Individual III-9 had a histologically verified sebaceous cyst removed from her scalp at the age of 12 years. These individuals gave no history suggestive of neurological dysfunction. Their general and neurological examinations were unremarkable and their MRI scans were normal.

Individuals IV-1 and 2 are reported by their mother not to have FAPor Gardner's syndrome but it is unclear to what extent, if any, this has been investigated.

Individual IV-3, aged 16 years, had the resection of a histologically verified fibroma of the left trapezius muscle. Radiological investigations have revealed osteomas of the left frontal bone, orbital rim, and of both mandibles, as well as dental inclusions and supernumerary teeth. Sigmoidoscopic examination identified what proved to be, on histological examination, a tubular adenomatous polyp. A CT scan of the head performed without the intravenous infusion of contrast material is reported to be normal except for the presence of bilateral ethmoidal osteomas.

\section{Discussion}

The occurrence of benign intracranial, nonneuroectodermal tumors in two related individuals with cranial and facial osteomas, constituting a new variant of Gardner's syndrome is presented.

\section{Inherited colorectal neoplasias and primary malignant brain tumors}

Two major forms of familial colorectal cancer syndromes are currently recognized: FAP and hereditary nonpolyposis colorectal cancer (Lynch syndrome). ${ }^{3}$ There has been much recent interest in the association of primary malignant brain tumors in the setting of inherited colorectal cancers. The original description by Turcot, Després and St. Pierre was of a brother and sister with numerous colonic polyps. ${ }^{4}$ The brother also had a colonic adenocarcinoma and a medulloblastoma invading the "medulla spinalis" (the brain was not examined) and his sister had a glioblastoma multiforme (GBM) and a small hypophyseal chromophobe adenoma. ${ }^{4}$ Since then there have been numerous reports of the association of inherited colorectal polyposis and malignant brain tumors under the eponym of Turcot's syndrome. The cerebral neoplasms associated with Turcot's syndrome have overwhelmingly been primary tumors of neuroectodermal, neuroglial origin, predominantly medulloblastomas and GBMs, although anecdotal cases of spongioblastomas (a tumor with histological features of both medulloblastoma and GBM), of an ependymoma and of lymphomas, have appeared. ${ }^{5}$ Some reports have suggested the existence of two variants of Turcot's syndrome: one in which a lesser number of colonic polyps is associated with GBMs and another where more numerous adenomatous polyps are associated with cerebellar medulloblastomas. ${ }^{6}$ This distinction has recently been characterized at the molecular level into two distinct entities: one in which the germ-line mutation of the APC gene characteristic of FAP is associated predominantly with cerebellar medulloblastomas and another, including the original family 
described by Turcot and his collaborators, where GBMs, predominantly, are associated with replication errors characteristic of hereditary nonpolyposis colorectal cancer (Lynch syndrome). ${ }^{3}$ A patient with "adenomatous polyposis" and a colonic adenocarcinoma who also had a craniopharyngioma, but whose sibship was free of colorectal polyps, has been reported; and a patient with a craniopharyngioma is listed in a cohort of patients with familial polyposis coli. ${ }^{7}$

\section{Familial adenomatous polyposis and Gardner's syndrome}

Familial adenomatous polyposis is an autosomal dominant disorder resulting from a mutation of the APC tumor suppressor gene residing at position 21-22 on the long arm of chromosome 5. ${ }^{1,8,9}$ Different families with FAP can have different mutations of the APC gene but all mutations are in stop codons and result in truncation of the APC protein. Gardner's syndrome is a variant of FAP with the same mutation of the APC gene ${ }^{1,10}$ but Gardner's syndrome is associated with characteristic osteomas of the skull, of the mandible, and, to a lesser extent, of the maxilla. ${ }^{11}$ Other common extracolonic manifestations of Gardner's syndrome include osteomas of the long bones; cutaneous epidermoid cysts, fibromas, leiomyomas, and lipomas; mesenteric desmoid tumors; peri-ampulary and duodenal carcinomas, hepatoblastomas, benign and malignant biliary and adrenal neoplasms; papillary carcinoma of the thyroid; and dental anomalies such as supernumerary teeth, odontomas, and a

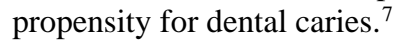

\section{Gardner's syndrome and intracranial tumors}

There have been only a few earlier reports of intracranial tumors occurring in the context of Gardner's syndrome: a family wherein Turcot's syndrome and Gardner's syndrome occurred in different individuals has been described, and a case suggesting the possible coexistence of Gardner's syndrome and Turcot's syndrome in the same individual has been reported. ${ }^{12,13}$ The presence of a nonhistologically verified cerebellar tumor in an individual who did not have colorectal polyps or carcinoma, but whose father and brother had Gardner's syndrome, has also been reported, as has the case of a patient with Gardner's syndrome and a brain metastasis from a rectal carcinoma. ${ }^{14,15}$ The author is not aware of any previous report describing the association of intracranial epidermoid cysts and meningiomas in patients with FAP or Gardner's syndrome.

\section{Intracranial epidermoid cysts and meningiomas \\ Epidermoid cysts}

Epidermoid cysts of the central nervous system are benign growths originating from an error in embryonic development that results in the inclusion of epidermal cells at the time of closure of the neural groove between the third and fifth week of gestation. ${ }^{16}$ They are located mainly, but not exclusively, within the posterior fossa of the cranium, especially the CPangle. They appear as a pearly tumor lined by a single layer of simple stratified squamous epithelium whose contents are soft and rich in cholesterol crystals perhaps resulting from prior hemorrhage in the lesion. ${ }^{16}$ Xanthochromia is not uncommon. The hyperdense appearance of the epidermoid cyst of our patient on CT and T-1 weighted MRI scanning is somewhat unusual but well-recognized $^{17,18,19}$ and likely is the result of prior hemorrhage. ${ }^{20}$
Although intracranial epidermoid cysts have not previously been described in Gardner's syndrome, subcutaneous epidermoid cysts are common in this condition. ${ }^{7}$ Subcutaneous and intracranial epidermoid cysts have identical histological features and it is tempting to postulate a common genetic origin for them in the setting of Gardner's syndrome.

\section{Meningiomas}

The etiology of meningiomas is unknown. They are of mesodermal origin and arise from arachnoidal cap cells (meningocytes) that are maximally concentrated at pacchionian granulations. ${ }^{21}$ A possible genetic determinant for the formation of meningiomas is suggested by their occurrence in neurofibromatosis type 2 , the central form of neurofibromatosis resulting from a lesion of chromosome $22^{22}$ and the presence of monosomy of chromosome 22 arising from deletion of its long arm in some sporadic meningiomas. ${ }^{22,23}$ Meningiomas have not been associated with mutations of the APC gene although, to our knowledge, such an association has not been sought. Histological confirmation of meningioma was not obtained in our patient. Its association with a diploic space could raise the possibility that it is, in fact, also an epidermoid cyst which, like meningiomas, can arise from diploic spaces. None of the other radiological features, however, supports the diagnosis of epidermoid cyst, while the radiological features, as a whole, can only support the diagnosis of meningioma. ${ }^{24}$

\section{Conclusions}

Our report indicates that hereditary colorectal cancers are associated with a much wider spectrum of benign and malignant brain tumors than previously thought. These occur in three distinct settings: 1) Hereditary nonpolyposis colorectal cancer (Lynch syndrome) and, mainly, glioblastoma multiforme; 2) FAP and, predominantly, cerebellar medulloblastomas; and 3) Gardner's syndrome and benign intracranial tumors such as epidermoid cysts and meningiomas. The occurrence of benign intracranial tumors in the patients presented may reflect a pleiotropic effect of the APC gene or the action of distinct modifying genes. Elective, noninvasive MRI should be considered for patients with FAP to ascertain the presence or absence of intracranial tumors.

\section{REFERENCES}

1. Powell SM, Petersen GH, Krush AJ, et al. Molecular diagnosis of familial adenomatous polyposis. N Engl J Med 1993;329:19821987.

2. Gardner EJ, Richards RC. Multiple cutaneous and subcutaneous lesions simultaneously with hereditary polyposis and osteomatosis. Am J Hum Genet 1953;5:139.

3. Hamilton SR, Liu B, Parsons RE, et al. The molecular basis of Turcot's syndrome. N Engl J Med 1995;332:839-847.

4. Turcot J, Després J-P, St Pierre F. Malignant tumors of the central nervous system associated with familial polyposis of the colon: report of two cases. Dis Colon Rectum 1959;2:465-468.

5. Kropilak M, Jagelman DG, Fazio VW, Lavery IL, McGannon E. Brain tumors in familial adenomatous polyposis. Dis Colon Rectum 1989;32(9):778-782.

6. Itoh $\mathrm{H}$, Ohsato K, Yao T, Iida M, Watanabe H. Turcot syndrome and its characteristic colonic manifestation. Dis Colon Rectum 1985;28:399-402.

7. Koot RW, Hulsebos TJM, van Overbeeke JJ. Polyposis coli, craniofacial exostosis and astrocytoma: the concomitant occurrence of the Gardner's and Turcot's syndromes. Surg 
Neurol 1996;45(3):213-218.

8. Nighisho I, Nakamura Y, Miyoshi Y, et al. Mutations of chromosome 5q21 genes in FAP and colorectal carcinoma patients. Science 1991;253:665-669.

9. Bodmer WF, Bailey CJ, Bodmer J, et al. Location of the gene for familial adenomatous polyposis on chromosome 5. Nature 1987;328: 614-616.

10. Groden J, Thilveris A, Samowitz W, et al. Identification and characterization of the familial adenomatous polyposis coli gene. Cell 1993;66:589-601.

11. Jagelman DG. Extracolonic manifestations of familial polyposis coli. Semin Surg Oncol 1987;3:88-91.

12. Lasser DM, De Vivo DC, Garvin J, Wilhelmsen KC. Turcot's syndrome: evidence for linkage to the adenomatous polyposis coli (APC) locus. Neurology 1994;44:1083-1086.

13. Erwald R. Gardner's syndrome with adenoma of the common bile duct. A case report. Acta Chir Scand Suppl 1984;520:63-68.

14. Terao H, Sato S, Kim S. Gardner's syndrome involving the skull, dura and brain. J Neurosurg 1976;44:638-641.

15. Russel DS, Rubinstein LJ. Epidermoid Cysts (cholesteatoma., In: Edward Arnold (ed). Pathology of Tumours of the Nervous System, 1977;30-32.
16. Braun IF, Naidich TP, Leeds NE, et al. Dense intracranial epidermoid tumors. Radiol 1977;122:717-719.

17. Gualdi GF, Biasi C Di, Trasimeni G, et al. Unusual MR and CT appearance of an epidermoid tumor. AJNR 1991;12:771-772.

18. Tekkok IH, Cataltepe O, Saglas S. Dense epidermoid cyst of the cerebellopontine angle. Neuroradiol 1991;33:255-257.

19. Truwit CL, Lempert TE. Pediatric Neuroimaging: A Casebook Approach. Denver: DPS Press, 1991; 264-270.

20. Burger PC, Scheithauer BW (eds). Tumors of the Central Nervous System. Washington: Armed Forces Institute of Pathology, 1994; 259-286.

21. Rouleau GA, Wertelecki W, Haines JL, et al. Genetic linkage of bilateral acoustic neurofibromatosis to a DNA marker on chromosome 22. Nature 1987;329:246-248.

22. Zang KD, Singer H. Chromosomal constitution of meningiomas. Nature 1967;216:84-85.

23. Atlas SW (ed). Magnetic Resonance Imaging of the Brain and Spine, 2nd Edition. Philadelphia-New York: Lippincott-Raven, 1966;424-446.

24. Bigorgne JC, Fanello S, Rohmer V, et al. Craniopharyngioma associé à une polypose rectocolique: syndrome de Turcot? Gastroenterol Clin Biol 1983;7(12):1047. 